\title{
MUDANÇAS CLIMÁTICAS E O TURISMO: DESAFIOS E POSSIBILIDADES
}

\author{
GRIMM, Isabel Jurema - isabelgrimm@gmail.com \\ PRADO, Lilliam - lilliamrprado@gmail.com \\ GIACOMITTI, Renata Brockelt - renatagiacomitti@hotmail.com \\ MENDONÇA, Francisco - chico@ufpr.br \\ PPGMADE / UFPR - Universidade Federal do Paraná
}

\begin{abstract}
Resumo
Eventos climáticos têm variações decorrentes de causas naturais, mas, o ser humano, tem sido apontado como o principal responsável pelas mudanças climáticas na atualidade. 0 turismo representa uma das atividades socioeconômicas de interferência e sensibilidade diante ao cenário projetado pelas mudanças climáticas. No entanto, tais mudanças são caracterizadas pela imprevisibilidade e sua repercussão ainda é pouco conhecida pelo setor turístico. Na tentativa de tecer reflexões sobre a temática, o presente artigo parte da revisão da literatura, desenvolvendo questões e diálogos interdisciplinares para compreender se é possível estabelecer relações consistentes entre mudanças climáticas globais e a realidade local vivenciada nos destinos turísticos do litoral paranaense. Tal trajetória mostrou-se complexa, sobretudo quando confrontada a discrepância entre discursos científicos, ideológicos e políticos, incompatíveis para efetivação de planos de mitigação de impactos socioambientais envolvendo o setor turístico.
\end{abstract}

Palavras-chave: Mudanças climáticas, clima, turismo.

CLIMATE CHANGE AND TOURISM: CHALLENGES AND OPPORTUNITIES

Abstract

Weather events have variations due to natural causes, but humans have been identified as the main cause of climate change today. Tourism is one of the socioeconomic activities of interference and sensitivity to the scenario projected by climate change. However, such changes are characterized by unpredictability and its impact is still little known by the tourism sector. In an attempt to weave reflections on the subject, this article part of the literature review, developing issues and interdisciplinary dialogues to understand whether it is possible to establish consistent relationships between global climate change and the reality experienced in the local tourist destinations of the coast of Paraná. This course proved to be complex, especially when confronted the discrepancy between scientific discourses, ideological and political incompatible for effective mitigation plans involving social and environmental impacts of the tourism industry.

Key Words: Climate change, climate, tourism.

\section{INTRODUÇÃO}

A compreensão sobre as mudanças climáticas requer a inclusão de um amplo espectro de perspectivas sob diálogos interdisciplinares, pois se trata de um conhecimento sistêmico e complexo, remetendo a necessidade de uma racionalidade ambiental compatível à leitura e interpretação dos fenômenos naturais e sociais em ritmos e intensidades díspares.

A estruturação dessa trajetória reflexiva sobre os aspectos climáticos e o turismo no litoral do Paraná foi elaborada com base da literatura, e inserção de novas reflexões (re)interpretações e questionamentos sobre o estado da arte, as condições e relações possíveis diante ao arcabouço teórico sobre o tema e os limites diante as condições que imperam na construção do conhecimento cientifico.

Inquietações que motivaram esse estudo estão relacionadas à compreensão da dinâmica e paradoxos que envolvem a relação entre ambiente e desenvolvimento. Diante dessa possibilidade, grande repertório de questões- 
problemas foi lançado, dentre as quais se destaca: compreender em que medida as mudanças climáticas e o turismo no litoral do Paraná se apresenta possíveis. A sistematização de uma metodologia que pudesse orientar a resposta dessa questão mostrou-se árdua diante à complexidade do tema.

$\mathrm{Na}$ abertura, o primeiro item delimita o referencial teórico-metodológico do campo de conhecimento da ciência geográfica e especificamente da climatologia. Tal referencial volta-se à importância da relação sociedade-natureza e, nesse caso a geografia apresenta compatibilidade dialógica desejável a essa articulação e são apresentadas algumas noções elementares sobre a gênese, hipóteses e discurso envolvendo as mudanças climáticas globais. Nesse contexto, assume-se como premissa a abordagem cientifica enquanto um conhecimento discutível e questionável. Os argumentos apresentados primam pela objetivação na apreensão da realidade, embora se reconheça a impossibilidade da neutralidade do sujeito-pesquisador. De qualquer maneira, procura manter a clareza diante a relatividade dos fatos, assumindo uma posição prudente e preventiva diante a incerteza e imprevisibilidades envolvendo as mudanças climáticas. No segundo item, observa-se a relação entre clima e turismo, considerando as diretrizes e condições apresentadas por órgãos governamentais e internacionais. Nesse ponto, algumas lacunas impediram a fluência das afirmações uma vez que a revisão do tema na literatura do campo do turismo mostrou-se escassa. Todavia, o turismo em si contempla amplo panorama no cenário mundial, sobretudo envolvendo planos estratégicos de ampliação das atividades do setor, bem como discursos sobre os cenários atuais e projeções no que diz respeitos a sua participação na mitigação dos impactos ambientais em escala global. O terceiro item procura transpor diálogos analisando dinâmicas e vulnerabilidades da zona costeira paranaense com a necessidade de medidas de mitigação e adaptação da atividade turística às mudanças do clima, entendendo que, quanto menos eficazes ou inexistentes forem as ações tomadas, maiores serão as dificuldades para adaptações sociais e econômicas no futuro, sobre tudo em regiões cuja economia depende quase exclusivamente do turismo.

\section{MUDANÇAS CLIMÁTICAS: GÊNESE, HIPÓTESES E DISCURSOS.}

A compreensão sobre as mudanças climáticas requer perspectivas sistêmicas e complexas dos fenômenos sociais e naturais, sendo possível encontrar contribuições nos mais distintos campos do conhecimento. A climatologia, especificamente, apresenta contribuições importantes, vez que estuda os fenômenos que acontecem na Troposfera englobando o conjunto de sistemas naturais que estão em constante conexão e dinamismo: hidrosfera, litosfera e atmosfera - o que representa um vasto universo de elementos e sistemas. A troposfera corresponde à camada da atmosfera onde há condições ambientais para o desenvolvimento da vida (biosfera). Portanto o estudo do clima está diretamente relacionado ao campo de conhecimento que tem como unidade analítica central a relação sociedade-natureza. 
Contudo, o entendimento sobre mudanças climáticas remete à história geologia da Terra. A paleoclimatologia apresenta dados de grande relevância para compreensão da dinâmica do Planeta durante diversas eras ou períodos glaciais e interglaciais. Conti (1998) apud Mendonça (2007) hierarquizou as diferentes eras das modificações pelas quais o planeta teria passado, as quais desencadearam naturalmente mudanças climáticas significativas (tabela 01). É preciso enfatizar que a Terra sofre influências determinantes de fatores externos ao próprio planeta, fato reconhecido há muito tempo pelas ciências.

Tabela 01 - Hierarquização das modificações Globais dos Climas.

\begin{tabular}{|ccc|}
\hline TERMO & DURAÇÃO & CAUSAS PROVAVEIS \\
\hline $\begin{array}{c}\text { Revolução } \\
\text { Climática }\end{array}$ & $\begin{array}{c}\text { Superior a } 10 \text { milhões de } \\
\text { anos }\end{array}$ & $\begin{array}{c}\text { Atividades geotectônicas e possíveis } \\
\text { variações polares. }\end{array}$ \\
\hline $\begin{array}{c}\text { Mudança } \\
\text { Climática }\end{array}$ & $\begin{array}{c}10 \text { milhões a } 100 \mathrm{mil} \\
\text { anos }\end{array}$ & $\begin{array}{c}\text { Mudanças na orbita de translação } \\
\text { e na inclinação do eixo terrestre. }\end{array}$ \\
\hline $\begin{array}{c}\text { Flutuação } \\
\text { Climática }\end{array}$ & 100 mil anos a 10 anos & $\begin{array}{c}\text { Atividades vulcânicas e mudanças } \\
\text { na emissão solar. }\end{array}$ \\
\hline $\begin{array}{l}\text { Interação } \\
\text { Climática }\end{array}$ & Inferior a 10 anos & $\begin{array}{c}\text { Interação atmosfera-oceano. } \\
\text { Alteração } \\
\text { Climática }\end{array}$ \\
\hline Muito curta & $\begin{array}{c}\text { Atividade antrópica, urbanização, } \\
\text { desmatamento, } \\
\text { armazenamento de água ,etc. }\end{array}$ \\
\hline
\end{tabular}

Fonte: CONTI, 1998 - apud, MENDONÇA, 2007.

A fonte primária de energia para o planeta Terra é o Sol - de natureza dinâmica e não linear. As variações solares são diversas e podem ser relacionadas a alterações do campo magnético, manchas solares e ciclos. A abordagem de ciclos solares torna-se eficiente na busca da compreensão relacional e sistêmica dos fenômenos climáticos, tais como os ciclos: decadal do Pacifico ${ }^{1}$ ( $\sim 11$ anos), o ciclo de Gleissberg ${ }^{2}$ ( 90 anos), ciclos de Milankovitch ${ }^{3}$ entre outros.

Durante os períodos glaciais as médias das temperaturas globais são extremamente baixas (inferiores a $0^{\circ} \mathrm{C}$ ) e níveis dos oceanos reduzidos, em função da formação de geleiras. Já os períodos interglaciais, são caracterizados pelo aumento da temperatura global média e derretimento das geleiras de grande parte do globo terrestre. A dinâmica da órbita terrestre ao redor do Sol permite que a radiação solar atinja a superfície em diferentes graus de

\footnotetext{
${ }^{1}$ Oscilação Decadal do Pacífico (ODP) = Pacific Decadal Oscillation (PDO). A designação PDO deve-se a Steven Hare e Robert Francis, que a propuseram entre 1995/96, ao pesquisar conexões entre "ciclos" de produção de salmão no Alaska e condições climáticas no Oceano Pacífico (Hare e Francis, 1995).

2 O ciclo Gleissberg é um período aprox. 90 anos - que aparentemente causou um resfriamento na temperatura global, mas, suficiente para causar algumas alterações climáticas consideráveis.

3 Milution Milankovic, (1879-1958) foi um cientista sérvio que contribuiu para a ciência mundial. Com a teoria sobre o "cânone da Terra Insolação", que caracteriza o clima de todos os planetas do sistema solar. E a explicação da Terra em longo prazo mudanças climáticas causadas por mudanças na posição da Terra em relação ao sol, conhecido como ciclos de Milankovitch.
} 
intensidade, o que desencadeia uma redistribuição contínua de energia térmica e viabiliza diferentes escalas de mudanças na temperatura da superfície.

A dinâmica astrofisica, sobretudo considerando o Sol e o movimento orbital da Terra, tem uma importância fundamental na formação e dinâmica da atmosfera do Planeta, relacionado aos eventos climáticos como as eras glaciais e interglaciais. A oscilação desse movimento é conhecida como Ciclos de Milankovitch, que controla a radiação solar que incide na Terra. Portanto, a energia provinda do Sol, que atinge a superfície da Terra é o fator mais importante no desenvolvimento dos processos físicos que geram o tempo meteorológico e o clima.

\begin{abstract}
A dinâmica climática é condicionada, primariamente, pela radiação solar, que é a fonte básica de energia para a Terra. Cerca de 30\% dessa radiação são refletidos, imediatamente ao adentrar a atmosfera terrestre, de volta para o espaço, dos quais as nuvens são responsáveis pela metade $(15 \%)$ e os $15 \%$ restantes, pelos aerossóis e moléculas que compõem a atmosfera e pela superfície terrestre, sem produzir qualquer aquecimento. A proporção entre a radiação refletida e a incidente é chamada albedo, que é variável para diferentes tipos de superfície a exemplo dos oceanos - cerca de $10 \%$, e a neve e o gelo - em torno de 90\% (LINO, 2009, p.8 apud MENDONÇA, 2011, p 31).
\end{abstract}

Os oceanos, por sua vez, constituem outro fator decisivo na regulação do clima global. É essencial observar as características dos oceanos e suas influências no clima da Terra, em todas as latitudes e considerando as suas configurações geográficas, a distribuição das suas propriedades conservativas, a circulação das massas de água em diversas escalas, os diversos indicadores biológicos, os gases dissolvidos nas águas dos mares e a importância crucial das nuvens que pode tanto refletir calor como absorver calor, portanto, representando mais uma interrogação da complexa equação do clima.

O terceiro fator central na configuração do clima global refere-se às nuvens e a circulação das massas de ar na atmosfera. Um dos fatores mais desconhecidos e incertos sobre o seu funcionamento, dado do dinamismo dos seus fenômenos. Além disso, as nuvens podem tanto refletir calor como absorver calor, portanto, representa mais uma interrogação da complexa equação do clima. O problema reside justamente acerta o equilíbrio dessa complexa relação. A incerteza sobre o funcionamento do efeito estufa e o aquecimento global esbarra-se na falta de conhecimento suficiente sobre a função das nuvens e dos oceanos no clima. Ambos têm enorme influência no equilíbrio térmico do planeta, porém as nuvens podem refletir radiação e também retê-la, enquanto os oceanos absorvem o calor, retardando o aumento dele na atmosfera. O problema reside justamente acerta o equilíbrio dessa complexa relação.

Pesquisas sobre o clima ganham evidencia mundial diante a possibilidade do impacto e desequilíbrio ${ }^{4}$ ambiental gerado pela ação humana, a partir 1980, com um imenso repertório de produções cientificas e jornalísticas com perspectivas

\footnotetext{
${ }^{4}$ Desequilíbrio é um conceito que pode conduzir a equívocos. Não existe equilíbrio estático na natureza - ela está sempre em movimento e apresenta oscilações, portanto em um desequilíbrio natural e dinâmico.
} 
variadas, discordantes e antagônicas. Diante ao volume de demandas, estudos e repercussão sobre o tema são convocadas uma serie de Convenções e Congresso para discutir, divulgar e propor planos de ação diante aos cenários alarmantes envolvendo as mudanças climáticas. Foi nesse contexto que a ONU cria o IPCC.

A hegemonia de grande parte da comunidade cientifica sobre o aquecimento global, torna ainda mais importante o cuidado e a necessidade de estudos sobre os pesquisadores que apresentam argumentações distintas, sobretudo, quando os mesmo representam importantes cientistas voltados aos estudos do tema.

\begin{abstract}
(...) ainda que um conjunto representativo de cientistas de todo o mundo tenha se pronunciado publicamente afirmando que as temperaturas médias do planeta aumentaram cerca de $1,5^{\circ} \mathrm{C}$ nos dois últimos séculos, e que ocorrerá uma intensificação da ordem aproximada de $2^{\circ} \mathrm{C}$ a $6^{\circ}$ no século XXI, algumas vozes dissonantes de cientistas que apontam para a ocorrência de um fenômeno contrário a este consenso tem evidenciado a necessidade do aprofundamento do debate acerca das mudanças climáticas globais (...) (MENDONÇA, 2006, p.14).
\end{abstract}

Um dos documentos mais importantes e vigentes do IPCC, o AR4 apresenta uma perspectiva sistêmica sobre as mudanças climáticas, bem como enfatiza a relação entre sociedade natureza, caracterizando enfaticamente a ação antrópica como nuclear em seus estudos como indicativo as argumentações sobre o aquecimento. O sistema natural consta, como um atributo de menor significado nos processos e causas das dinâmicas climáticas.

A evidência de que alguns gases, como o gás carbônico e o metano, agem como regulador da temperatura terrestre foi apresentado em 1859 por John Tyndall ${ }^{5}$. Seus estudos avançaram sobre as pesquisas de Joseph Fourier (1768-1830). Tyndall desenvolveu pesquisas em torno do fenômeno natural conhecido como efeito estufa. Em equilíbrio dinâmico os gases do efeito estufa garantem em sua atuação a composição necessária à vida, mas em excesso ou escassez pode acarretar em efeitos maléficos. O efeito estufa indica que existe um processo de radiação solar de ondas longas e curtas em função do albedo ${ }^{6}$.

Portanto, os gases do efeito estufa (GEE) existem naturalmente e garantem o equilíbrio dinâmico necessário à vida, mas em excesso ou escassez podem acarretar em problemas que são investigados até os dias atuais, pois o conhecimento desse processo entrelaçado a variáveis de natureza dinâmica é de difícil precisão e condições de mensurar seus efeitos. A figura - 01 foi elaborada tendo com fonte de informação os dados do IPCC e, evidencia progressivo

\footnotetext{
5John Tyndall (1820-1893) testou de que forma alguns gases permitiam que a radiação do Sol penetrasse a atmosfera, mas conseguiam barrar depois o calor emitido pela superfície terrestre em forma de raios infravermelhos. O experimento testou diferentes concentrações de vapor da água e o chamado "gás-carvão", uma mistura de $\mathrm{CO} 2$, metano $(\mathrm{CH} 4)$ e hidrogênio, e quanta energia era absorvida. Para tanto, usou fontes de calor que emitiam radiação infravermelha dentro de um tubo onde dosava diferentes concentrações dos gases, medindo a energia que passava com uma pilha termoelétrica (que funcionava à base de calor).

${ }^{6} \mathrm{O}$ albedo constitui a capacidade dos materiais e superfícies em refletir ou absorver o calor, ele representa, portanto um índice de reflexão dos raios solares. A superfície do planeta é diversa, logo esse índice varia bastante, nas cidades, o índice de absorção do calor é alto dado a pavimentação do solo e as sombras dos edifícios, portanto cerca de $80 \%$ do calor é absorvido. Nas áreas verdes, como florestas, refletem o calor, por isso costuma apresentar sensação térmica mais "refrescante".
} 
aumento das atividades antropogênicas em função do aumento da temperatura no Planeta.



Figura 1

Gases do efeito estufa - Atividades Antropogênicas.

(Fonte: http://www.ipcc.ch/graphics/syr/fig2-1.jpg)

Se de um lado a perspectiva hegemônica concentrada no IPCC indica o aquecimento global em decorrência das atividades antropogênicas ${ }^{7}$, do outro, pesquisadores contrários a essa hipóteses argumentam que as alterações antrópicas são insignificantes diante a fatores de ordem astrofísicas e geofísicas. E justificam que ainda que haja tais impactos, esse é considerado de pequena proporção quando comparado a enorme e decisiva importância de aspectos como os ciclos solares ou a dinâmica dos oceanos interagindo com a atmosfera. De acordo com Felício et al., (2012):

\begin{abstract}
Deve-se ressaltar que a influência do vapor d'água no clima da Terra é de suma importância. Sua capacidade de transferir calor, e manipular colossal quantidade de energia são superiores a qualquer gás estufa provenientes das cartilhas do IPCC. Este fato tem que ser levado em conta nos processos climáticos. Se há queimas, de qualquer espécie natural, ou de processos antropogênicos, a principal contribuição desta será o vapor d'água liberado para a atmosfera, e não os gases de ínfima parte, como o CO2 (FELICIO et al., 2012, p.12).
\end{abstract}

O aparato tecnológico nesse contexto das mudanças climáticas, tem sido de grande valia, mas, é preciso ponderar quando modelos matemáticos tem maior credibilidade do que pares científicos discordantes. Atualmente, os modelos

\footnotetext{
${ }^{7}$ Foi a partir deste período que documentos passaram a fazer menção à necessidade de se proteger o meio ambiente, tendo em vista as incertezas científicas existentes. Na Convenção de Viena muito se discutiu sobre a necessidade de proteção da Camada de Ozônio, onde foi elaborado um dos primeiros documentos que tratou, sobre a necessidade de redução da influência da ação humana sobre o meio ambiente, especialmente quanto à necessidade de se reduzir a produção e comercialização de gases que destroem a camada de ozônio. Entretanto, são outros dois documentos os considerados marcos histórico para mitigação da ação humana dentro do campo de mudanças climáticas: a Convenção Quadro das Nações Unidas sobre Mudanças do Clima, ocorrida na Cúpula da Terra (ECO92), e o Protocolo de Quioto, elaborado a partir da Conferência das Partes da Convenção sobre Mudanças do Clima.
} 
matemáticos aplicados a análise do clima simulam e projetam cenários futuros considerando como hipótese que a ação antrópica é a gênese do aquecimento global. Para calcular esses dados foi definido como parâmetro, a Sensibilidade Climática $\left(\mathrm{SC}^{8}\right)$, mas esse método apresenta uma considerável margem de erro e incertezas.

Essa incerteza sobre a (SC) é geradora de polêmicas sobre o tema. Isso acontece, pois, parte da comunidade cientifica afirmam que a temperatura perderia o controle se a concentração de gás carbônico ultrapassasse 450 (ppm), chefes de estado adotam até $550(\mathrm{ppm})$ nas negociações do novo acordo climático na ONU. Contudo, é possível delimitar um repertório de questõesproblemas, orientações de estudos de casos e possibilidades de tratamento metodológico envolvendo a questão climática. De acordo com Mendonça (2011) é possível refletir sobre o tema considerando quatro eixos de análise:

\begin{abstract}
Primeiramente a referência à participação antropogênica no aquecimento global; segundo a possibilidade (ou não) de amenizar esse fenômeno climático e como isso deve ser realizado; terceiro a temporalidade dos efeitos do aquecimento sobre a sociedade e o meio ambiente; e quarto a severidade desses efeitos (MENDONÇA, 2011, p.34).
\end{abstract}

Percebe-se que as mudanças climáticas, não tem uma dimensão linear, previsível e padronizada. Não há como afirmar de maneia contundente sobre o caos em todos os lugares do planeta. Mais uma vez, a prudência sobre o cuidado metodológico ao delimitar a escala, contexto do estudo podem ser indicativos de uma maneira mais próxima e cautelosa para tratar as mudanças climáticas.

\title{
3 TURISMO E MUDANÇAS CLIMÁTICAS: IMPLICAÇÕES E DESAFIOS.
}

O turismo é analisado como alternativa para promoção do desenvolvimento econômico, ganhando visibilidade no cenário mundial. Muito além de um fenômeno econômico, o turismo é uma realidade social que tem se afirmado em numerosos países e uma atividade que abrange completa gama de atividades econômicas e sociais. Contudo, é um setor bastante suscetível, com irrefragáveis incidências sazonais, depende das condições geoclimaticas, da paz, da segurança, e da estabilidade do país ou região receptora, como da plasticidade da economia de mercado. Para Matzarakis (2008):

A interação entre o clima e o turismo apresenta duas vertentes. Por um lado, o turismo afeta o clima e é responsável por $5 \%$ das emissões dos gases com efeito de estufa. Por outro lado, o clima - aquecimento global - e as condições do tempo são os principais

\footnotetext{
${ }^{8} \mathrm{SC}=$ expressa a resposta de equilíbrio do clima em termos de elevação de temperatura média global, à forçante das emissões de gases de efeito estufa (GEE). Para efeitos de calibração desses modelos convencionou-se utilizar o valor da sensibilidade climática correspondente à duplicação da concentração atmosférica de $\mathrm{CO}_{2}$ relativamente àquela que existia na época da Revolução Industrial (260 ppmV), que denotaremos por $\mathrm{SC}_{2 \times \mathrm{CO}_{2}}$.
} 
fatores promotores do turismo e do recreio ao ar livre, conjuntamente com a natureza e a paisagem (MATZARAKIS, 2008, p. 01, tradução nossa).

Os destinos turísticos se alicerçam num conjunto de fatores de interligação climática, paisagística, ambiental, patrimonial, cultural, gastronômica, de lazer entre outros que interferem nas motivações dos visitantes e determinam boa parte dos fluxos e tendências de procura turística. A relação clima turismo é ampla admitindo a correlação do clima (causal) com o comportamento da sociedade (racional), ou seja, a motivação do turista em deslocar-se para determinado destino turístico está diretamente relacionado ao clima do lugar e as demandas sociais de comportamento.

O clima tem sido identificado como um fator-chave para o turismo e um atributo importante para os destinos turísticos (HU \& RITCHIE, 1992) ou é muitas vezes o principal recurso, por exemplo, no caso dos destinos de praia (KOZAK et al., 2008) cuja imagem do destino e a preferência dos turistas para locais específicos são influenciados pelas condições do tempo. O clima de acordo com Andrade (2006) possui influência preponderante na sazonalidade, continuidade e regularidade dos fluxos turísticos que se dirigem ao núcleo receptivo.

Contudo, até recentemente, tanto o setor turístico como a comunidade acadêmica, pouco haviam pesquisado quer sobre os impactos das alterações climáticas na atividade turística quer, inversamente, sobre o peso que o turismo e atividades com ele relacionadas têm surtido nas mudanças ambientais globais (SCOTTS et al., 2009).

De acordo com a figura -02, o Brasil ou mais especificamente a América do Sul não está tão vulnerável às mudanças climáticas, cujos efeitos (FE) maior número de fenômenos extremos; (PDBT) perda de biodiversidade biológica terrestre; (PDBM) perda de biodiversidade biológica marinha e (APV) aumento dos preços das viagens como consequência da política migratória são os principais impactos das mudanças climáticas nos destinos turísticos. 




Figura 02

Distribuição geográfica dos principais impactos das mudanças climáticas nos destinos turísticos.

(Fonte: Organização Mundial do Turismo (OMT) / Programa das Nações Unidas para o Meio Ambiente (PNUMA) 2008, Mudanças Climáticas e Turismo - Responder aos Desafios Mundiais, Sumário, OMT; Madri).

Porém, ações localizadas contribuem para aumentar os efeitos negativos das mudanças climáticas em contexto global, decorrendo em eventos extremos que podem afetar os destinos turísticos considerados mais vulneráveis. Parece não haver nenhum estudo que forneça evidências diretas sobre o crescimento econômico e a estabilidade social e política ligada à mudança climática e como isso afetaria o turismo, pois, são poucos os estudos que avaliam as consequências da política de mitigação no turismo para os efeitos das mudanças climáticas (SCOTT et al., 2009). A literatura focaliza as consequências indiretas da mudança climática, percebe-se a urgência de produzir o debate e pesquisa que relacione atividade turística e mudanças climáticas, sua intensidade e efeitos nos destinos turísticos. 
A partir da tabela - 02 é possível visualizar os principais eventos climáticos que poderão de maneira direta impactar os destinos turísticos. Eles estão relacionados ao aumento das temperaturas, ao aumento da frequência e intensidade das tempestades e alterações significativas das precipitações. Suas implicações sobre os destinos turísticos ainda não foram detalhadamente estudadas, carecendo de pesquisas principalmente na América do Sul em especial no Brasil.

Tabela 02 - Impactos climáticos: principais mudanças e implicações para os destinos turísticos mundiais.

\begin{tabular}{|c|c|}
\hline IMPACTOS & $\begin{array}{l}\text { IMPLICAÇÕES NO TURISMO } \\
\text { (efeitos derivados) }\end{array}$ \\
\hline $\begin{array}{l}\text { Temperaturas mais } \\
\text { quentes. }\end{array}$ & $\begin{array}{l}\text { Sazonalidade alterada, estresse térmico para os turistas, } \\
\text { custos de refrigeração, transmissão de doenças } \\
\text { infecciosas. }\end{array}$ \\
\hline $\begin{array}{l}\text { Se subir a temperatura } \\
\text { da superfície do mar. }\end{array}$ & $\begin{array}{l}\text { Aumento de branqueamento dos corais e de recursos } \\
\text { marinhos. Degradação na estética dos destinos de } \\
\text { mergulho, snorkel. }\end{array}$ \\
\hline Elevação do nível do mar. & $\begin{array}{l}\text { Erosão costeira, perda de área de praia, custos mais } \\
\text { elevados para proteger e manter a orla. }\end{array}$ \\
\hline $\begin{array}{l}\text { Precipitação r } \\
\text { aumento da ev }\end{array}$ & $\begin{array}{l}\text { Escassez de água, a concorrência sobre a água entre o } \\
\text { turismo e outros setores, desertificação. }\end{array}$ \\
\hline $\begin{array}{l}\text { Diminuição da camada de } \\
\text { neve, } \\
\text { encolhimento das geleiras. }\end{array}$ & $\begin{array}{l}\text { Ausência de neve nos destinos de inverno, aumento de } \\
\text { custos, estações de esportes de inverno mais curtos, } \\
\text { estética da paisagem reduzida. }\end{array}$ \\
\hline $\begin{array}{l}\text { Aumento da frequência } \\
\text { e intensidade } \\
\text { de tempestades extremas. }\end{array}$ & $\begin{array}{l}\text { Risco para instalações turísticas, aumento dos custos de } \\
\text { seguro, interrupção de lucros das empresas (lucros } \\
\text { cessantes). }\end{array}$ \\
\hline $\begin{array}{l}\text { Aumento da frequência } \\
\text { e intensidade das chuvas }\end{array}$ & $\begin{array}{l}\text { Inundações com danos } \text { ao patrimônio histórico } \\
\text { arquitetônico e cultural, à infraestrutura turística, e } \\
\text { alteração na sazonalidade. }\end{array}$ \\
\hline
\end{tabular}

Fonte: Adaptado por GRIMM a partir da OMT, do PNUMA e da OMM, 2007.

O sistema turístico está interligado por quatro elementos fundamentais - o espaço geográfico turístico, a demanda turística, a oferta turística e os agentes do sistema - que podem ser alterados direta ou indiretamente, pelos fenômenos das mudanças climáticas. No entanto ações de planejamento e intervenções permitem em tempo hábil que o setor possa agir sobre os diferentes elementos estruturando os possíveis efeitos derivados.

Efeitos decorrentes dos eventos climáticos aos quais os destinos turísticos estão expostos dependem da variabilidade natural do clima os quais, por sua vez, podem determinar a sazonalidade turística. Segmentos turísticos - sol e praia, ecoturismo, esportes de neve, entre outros - expostos a eventos climáticos poderão ser influenciados pela mudança climática, afetando sua infraestrutura e exigindo medidas de preparação para situações de emergência, elevando os gastos de manutenção e interrompendo por vezes a atividade comercial. Isso significa segundo a OMT (2007) que, mesmo sob condições atuais, a 
rentabilidade e viabilidade do destino são pelo menos parcialmente influenciadas pelo clima:

\begin{abstract}
El cambio climático tendrá en el sector turístico repercusiones tanto negativas como positivas que variarán apreciablemente por segmento del mercado y por región geográfica. La incidencia del cambio climático en una empresa o destino turístico cualquiera también dependerá en parte del efecto que tenga en la competencia. Cuando un elemento del sistema turístico sufre los efectos del cambio climático, puede que surjan oportunidades en otro ámbito. Por consiguiente, habrá ganadores y perdedores entre las empresas, los destinos y las naciones (OMT, 2007, p. 09).
\end{abstract}

O aumento da temperatura global poderá encurtar o período das estações de inverno, diminuindo as camadas de gelo nessas regiões, e seus efeitos além de diminuir o potencial turístico, poderiam inclusive vir a inviabilizar a realização do turismo, gerando toda uma problemática econômica e social nas regiões mais afetadas. Contudo, há o outro lado da situação, pois, da mesma forma que a mudança climática poderá inviabilizar a prática do turismo em regiões mais conhecidas, poderá destacar o potencial turístico de regiões pouco exploradas. É importante que se perceba a relação de reciprocidade existente entre o turismo e mudança climática, como a mudança no clima irá afetar a atividade turística, e como a poluição gerada pelo turismo contribui para o aquecimento global.

Debates e encontros têm discutido a questão das mudanças climáticas e o turismo a nível internacional. A $1^{\text {a }}$ Conferencia Internacional sobre Mudanças Climáticas e Turismo realizado na Tunísia em 2003, estabeleceu marco de ações para empresários e setor público, diante do compromisso da organização com o desenvolvimento sustentável e o combate à pobreza e como o turismo pode contribuir para o alcance desta meta. Mas, as discussões ganharam força em 2007, na segunda edição do evento, que aconteceu em Davos ${ }^{9}$, na Suíça. Na ocasião, constatou-se que:

O clima é um elemento fundamental para a existência do turismo, que deverá ser duramente afetado por conta do aquecimento global; que é cada vez mais urgente adotar políticas que considerem o turismo como um meio para a redução da pobreza e o enfrentamento do desafio das mudanças climáticas e que encorajem o setor a agir com responsabilidade ambiental, social, econômica e climática; que o turismo precisa mitigar suas emissões de gases de efeito estufa, especialmente as provenientes de transporte e hospedagem; há que se pensar em meios de adaptar o negócio turístico e os destinos às inevitáveis mudanças do clima; que é fundamental usar as tecnologias já existentes e criar novas que garantam a eficiência energética e que será necessário garantir recursos financeiros para ajudar as regiões mais pobres a lidar com os efeitos das mudanças climáticas (DAVOS DECLARATION, 2007, p. 1 - 4).

\footnotetext{
${ }^{9}$ Nesta edição nasceu o documento, "A Declaração de Davos" cujo resultado serviu de base para a Cúpula OMT Ministro do Turismo e Mudanças Climáticas, marcada para o Mundo Travel Market, em Londres, Reino Unido, em novembro de 2007. Foi apresentada para aprovação na Assembleia Geral da OMT em Cartagena das Índias, Colômbia, em novembro 2007, e também apresentada na Conferência sobre Mudanças Climáticas das Nações Unidas em Bali, Indonésia, em dezembro de 2007. Documento na integra disponível em: http://sdt.unwto.org/sites/all/files/docpdf/davosdeclaration.pdf.
} 
No Brasil o tema ganha visibilidade no Congresso Nacional em 2008, durante as comemorações do Dia Internacional do Turismo - 27 de setembro. Esta data foi dedicada à reflexão em todo o planeta sobre os impactos das mudanças climáticas provocadas pelo aquecimento global sobre as atividades turísticas. $\mathrm{Na}$ ocasião, a OMT propôs debater sobre um novo desafio: o de discutir, de maneira mais ampla e fundamentada, os impactos das alterações climáticas na operação e no desenvolvimento de destinos turísticos em todo o Planeta. Diante das preocupações com os efeitos do clima foi apresentada proposta da Política para as Mudanças do Clima e o Plano Nacional para adaptar e mitigar essas alterações, divulgando também o Fórum das Mudanças Climáticas no Brasil. O objetivo é estimular a sociedade brasileira a debater as mudanças do clima por meio da disseminação de informações acerca dos prováveis impactos desse fenômeno sobre a economia, a sociedade e os recursos naturais.

\subsection{O turismo e as ações de mitigação das mudanças climáticas.}

Estudos da OMT (2007) apontam que o crescimento vertiginoso do turismo internacional, mantendo-se as práticas atuais - em 1950, a atividade envolvia apenas 25 milhões de pessoas; hoje mobiliza cerca de 900 milhões de cidadãos em todo o mundo; em 2020, poderá chegar a 1,6 bilhão de turistas - resultará, em apenas três décadas, um aumento de $150 \%$ das emissões de gases do Efeito Estufa - dióxido de carbono - $\mathrm{CO} 2$, o óxido nitroso- N2O, o metano, $\mathrm{CH} 4$, o hexafluoreto de enxofre - SF6, os hidrofluorcarbonos - HFC, e os perfluorcarbonos, PFC - gases controlados pelo Protocolo de Quioto.

Durante a $2^{\mathrm{a}}$ Conferência Internacional sobre Turismo e Alterações Climáticas (Davos, Suíça, Outubro de 2007) uma equipe de especialistas da OMT, do PNUMA e da OMM formulou uma primeira tentativa de quantificação de emissões de GEE resultantes dos mais importantes subsectores turísticos - transporte, alojamento e atividades realizadas durante a estadia, de que são exemplo as visitas a museus, parques temáticos ou atividades de ar livre, como desportos (esqui, golfe). Este painel estimou a contribuição do turismo para a totalidade de emissões de gases em cerca de 5\%, em 2005 (SIMPSON, et al., 2008). O transporte aéreo segundo o mesmo autor origina, por si só, cerca de $40 \%$ destas. Impõe-se, por isso, que sejam tomadas medidas de mitigação e adaptação pelo setor turístico.

Gössling (2002) destaca que as repercussões da atividade turística refletem sobre maneira nas alterações e na ocupação e uso do solo, no consumo energético e na emissão de gases com efeito de estufa (Gee), na biodiversidade (introduzindo novas espécies, ou induzindo a extinção de espécies autóctones) e na difusão de doenças. $O$ autor demonstra ainda como o turismo pode potenciar mudanças na percepção ambiental dos turistas e introduzir alterações no consumo de recursos hídricos. Diante deste cenário, adotar práticas eficientes do ponto de vista ambiental deve-se, especialmente, pela pressão por parte do consumidor consciente em direção a padrões de produção e consumo 
sustentáveis, a redução de custos através do aperfeiçoamento da eficiência tecnológica que permite minimizar consumos e a subordinação dos empreendimentos turísticos às regulações existentes.

Gestionar os recursos e os territórios estão, por norma, entregues aos governos locais e nacionais. Portanto, é importante, que a preocupação com os efeitos das alterações climáticas seja incorporada e antecipada ao planejamento territorial e econômico. Para isso, o governo brasileiro tem tido um papel preponderante nos debates internacionais relacionados à questão do clima e tem avançado no diálogo sobre as medidas mitigadoras a serem implementadas no país pelos diferentes setores da economia. Internamente, construiu uma proposta de Política Nacional sobre Mudança do Clima, que vem se somar aos esforços já empreendidos pelo Congresso Nacional, nesse sentido. Um instrumento relevante da Política vem sendo também elaborado, trata-se do Plano Nacional sobre Mudança do Clima (PNMC), cujos objetivos permanentes são: reduzir as emissões antropogênicas de gases de efeito estufa e reforçar sumidouros de carbono no território nacional; definir e implementar medidas que promovam a adaptação à mudança climática por comunidades locais, municípios, estados, regiões e setores econômicos e sociais, especialmente aqueles que são mais vulneráveis aos efeitos adversos do clima.

O turismo tem um papel relevante nesse debate, por se tratar de um setor que é afetado pelos efeitos das mudanças do clima, mas que também contribui como parte importante de emissões de gases de efeito estufa, tendo em vista sua logística (transporte de passageiros) e infraestrutura (alojamento). Portanto, como dispõe a OMT (2007) é fundamental que a atividade turística busque a ecoeficiente empregando menos recursos e gerando menos resíduos, a partir de algumas ações como reduzir a intensidade com que emprega materiais; diminuindo consumo energético; eliminar a dispersão de produtos tóxicopoluentes; fomentar a reciclagem de materiais; maximizar o uso sustentável de recursos renováveis; ampliar a durabilidade dos produtos; promover a educação dos consumidores/clientes para um uso mais racional dos recursos naturais e energéticos.

\section{ZONA COSTEIRA PARANAENSE: DINÂMICAS E VULNERABILIDADES}

A região litorânea, pelos seus fatores determinantes climáticos característicos, é tradicionalmente objeto de estudo dentro do campo da metereologia e climatologia. Estas regiões apresentam aspectos importantes na análise ambiental - biodiversidade, geomorfologia - e socioeconômica - populacional, turismo e lazer (VANHONI \& MENDONÇA, 2008, p. 120).

Como um espaço de alta complexidade, as zonas costeiras configuram-se como uma área de transição (ODUM, 1988) abrangendo um mosaico de paisagens e um conjunto de fenômenos marcados por irregularidades, o que thes confere uma dinâmica, tais como ondas, marés, praias, correntes litorâneas, processos atmosféricos (CUNHA, 2007). É portanto, a dinâmica natural da costa marítima que define hábitos, usos e costumes deste território. 
O clima na planície litorânea apresenta média (anual e sazonal) entre $16^{\circ}$ e $18^{\circ} \mathrm{C}$ decaindo com o aumento a altitude. No verão a média apresenta-se entre 190 e $21^{\circ} \mathrm{C}$ e no inverno, as médias situam-se entre $12^{\circ}$ e $14^{\circ} \mathrm{C}$. Devido aos fatores estáticos e dinâmicos atuantes, o clima do litoral paranaense apresenta-se de maneira complexa e particular de acordo com Vanhoni e Mendonça (2008). A chuva varia sazonalmente, concentrando-se nos meses de verão, sendo que menores médias destacam-se nos meses de inverno.

(...) dados meteorológicos de inúmeras localidades na região Sul do Brasil constataram uma tendência à elevação das temperaturas em toda a região o que em termos gerais estima-se que nos últimos quarenta anos a temperatura média regional elevou-se cerca de $1,3^{\circ} \mathrm{C}$, o que teria sido acompanhado por uma elevação dos totais pluviométricos médios anuais.(...) as mais evidentes tendências de intensificação do aquecimento e da pluviosidade-umidade regional são mais evidentes no Estado do Paraná (...) (VANHONI e MENDONÇA, 2008, p. 01).

De acordo com Grimm (2010) na região costeira do Paraná a quantidade e distribuição das chuvas apresentam variações temporais e espaciais, dependendo da evapotranspiração, da energia solar disponível, da vegetação e das características do solo. Depende ainda da interação dos organismos vivos, incluindo a microfauna e a microflora. Qualquer alteração do clima ou da paisagem alterará a quantidade e a qualidade da água

Tanto a quantidade como a qualidade das águas sofrem alterações em decorrência de causas naturais ou antrópica. Entre as causas naturais que alteram o clima e, consequentemente, a disponibilidade de água, destaca-se a sazonalidade, além de outras variações climáticas naturais. Outras causas sem um ciclo determinado podem ser classificadas como "catástrofes". Entre as ações humanas que podem alterar o balanço hídrico, destacam-se em escala local e regional o desmatamento, a mudança do uso do solo, os projetos de irrigação e a construção de barragens. Em escala global, destaca-se a mudança climática decorrente da alteração das características químicas da atmosfera como gases que promovem o efeito estufa (Grimm, 2010, p. 160).

A região costeira representa um ecossistema frágil devido sua localização na interface continente-oceano-atmosfera. Esse espaço torna-se ainda mais vulnerável diante do uso e ocupação do solo considerando as atividades, portuárias, densidade demográfica, urbanização desordenada e o turismo de massa. Esse processo de interferência antrópica, de acordo com Marandola (2009) gera cenários de vulnerabilidade socioambiental, cujo grau de exposição ou suscetibilidade aos riscos e desastres, às fragilidades e capacidades das pessoas e sistemas naturais de passar pela experiência de perigo, a exemplo dos riscos das áreas fragilizadas diante as mudanças climáticas dependem da capacidade adaptativa e da magnitude da exposição dos sistemas a riscos eventos extremos.

O mar, a linha de costa e seus recursos naturais estão em contínuo movimento, num grau de intensidade maior que os fenômenos que conformam a terra firme, assim como os elementos característicos dos sistemas metereológicos e seus reflexos são igualmente móveis e praticamente intangíveis (CUNHA, 2007). O 
nível do mar, desde 1993, teve seu aumento estimado em 3,1mm/ano (2,4 a 3,8 ) devido principalmente, ao aquecimento global e, consequentemente, ao derretimento de glaciares e capas de gelo polares. Alterações nos regimes de chuvas foram observadas no início do século XX, e desde então, as precipitações aumentaram significantemente no leste da América do Norte e América do Sul. As mudanças no clima poderão afetar de forma mais propensa áreas costeiras, com alterações de ecossistemas devido ao aumento dos níveis do mar (IPCC, 2007).

Observando escalas regionais, nos últimos 6.000 ou 7.000 anos o mar tem permanecido mais estável, variando, em geral, menos que $10 \mathrm{~m}$, mas, estas variações são suficientes para provocar mudanças na zona costeira. No Paraná os balneários foram construídos em grande parte sobre terrenos que emergiram há menos de 5.000 anos e, neste período a variação do nível do mar em diversas regiões foi diferente (ANGULO, 2004). Dinâmicas de longo prazo que definiram a conformação geral da planície litorânea, devem ser compreendidos quando se objetiva prever qual o comportamento futuro da zona costeira frente a mudanças climáticas globais ou regionais. Angulo (2004) observa que a conjunção das variáveis de Milankovitch conduz a Terra para um novo período glacial e consequentemente de mar baixo. Supondo que o homem é o maior agente geológico do presente parece haver um esforço na tentativa de reverter esta tendência. Porém, salienta o autor, mesmo que as previsões de elevação do nível do mar se confirmem, o efeito desta elevação sobre as zonas costeiras deve ser diferente de acordo com suas características específicas e sua história evolutiva e cada caso deve ser analisado localmente, porém considerando as variáveis regionais e globais.

É o efeito combinado do vento com as ondas que provoca a elevação do nível do mar pelo empilhamento da água sobre a costa, a denominada maré metereológica. Estas marés de acordo com Angulo (2000) são irregulares, imprevisíveis e, probabilidades de sua ocorrência e seus efeitos não podem ser feitos com muita antecedência. Convém observar que quando a maré começa a subir tende a forçar a intensidade do movimento das ondas que se propaga em direção à costa, assim, em situações extremas Cunha (2007) destaca que as marés metereológicas têm um grande poder destrutivo, ocasionando inundações, ressacas e processos erosivos (figuras 03 e 04) e, que a rigor em cada situação de ondas e em cada ressaca a corrente de deriva - correntes que movimentam enorme quantidade de sedimento que são transportados ao longo do litoral - assume configurações próprias, com efeitos diferenciados. 

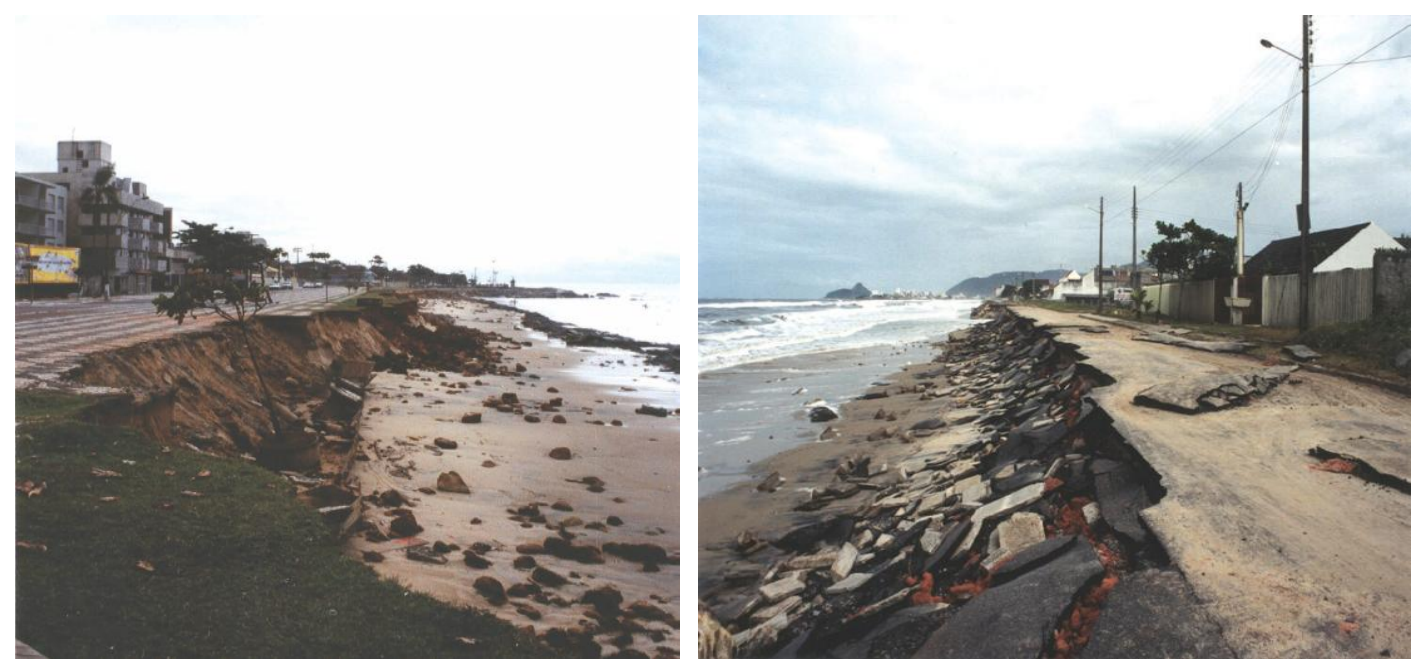

Figuras 03 e 04

Erosão na parte norte da Praia Brava de Caiobá após a ressaca de maio de 2001 e Avenida Beira Mar no Balneário Flamingo parcialmente destruído após a ressaca do mesmo período.

(Fonte: ANGULO, 2004).

Estes fenômenos são complexos, marcados pela interação de vários agentes e processos regulares e irregulares de natureza interna e externa, configurando a dinâmica da zona costeira. Destaca-se que a ação antrópica nessa dinâmica complexa pode gerar destruição e de acordo com Angulo (2000) qualquer obra que obstrua a deriva litorânea a montante gera erosão a jusante em função da decomposição praial. Dias et al., (2012) lembram que as zonas costeiras são afetadas também de forma positiva ou negativamente pelas intervenções feitas nas bacias hidrográficas, como pelas alterações no clima, pelas mudanças na agitação marítima e pelas transformações que induz no comportamento litosférico. O turismo contribui para as alterações, desde a ocupação desordenada do solo, contaminação da água por esgoto, nas emissões de gases do efeito estufa (liberação de dióxido de carbono - $\mathrm{CO} 2$ ), o que constitui questões que devem buscar ações de mitigação de seus impactos.

\subsection{A dinâmica do turismo no litoral paranaense.}

O homem coloca a natureza ao seu dispor, instituindo-se como espécie dominante e principal agente modelador das zonas costeiras. Com o poder tecnológico tenta assumir-se entidade reguladora dos processos dos quais depende, mas que mal conhece, que não controla, entrando em conflito consigo mesmo. Esses conflitos são manifestos na exploração dos recursos, no uso e ocupação turística, nas obras portuárias. Portanto, é essencial compreender como o litoral foi progressivamente ocupado, e como atividades humanas influenciam na dinâmica costeira (DIAS et al., 2012).

No Paraná as praias totalizam $126 \mathrm{~km}$, distribuídos de noroeste para sudeste, segundo Sampaio (2006). O uso do litoral para o turismo configurou a região como balneário, atividades de navegação recreativa e pesca esportiva, cujo 
processo envolve populações diferentes em diferentes ritmos, e até certo ponto, em diferentes espaços. Os turistas sazonais, e de segunda residência, ocupam áreas nobres. Migrantes e boa parte das pessoas de baixa renda, que vem ao litoral em busca de novas oportunidades, ocupam espaços menos valorizados. Os balneários se localizam nas praias mais abrigadas, onde morros próximos ou bancos de areia diminuem a energia das ondas. Tal o caso das praias mansas de Caiobá e Matinhos, Guaratuba e Pontal do Sul. No litoral norte, o processo de ocupação foi retardado pela falta de acesso terrestre e pela dificuldade do ingresso marítimo. Neste setor, todas as praias localizam-se em ilhas naturais ou artificiais. No litoral centro-sul, a ocupação ocorre junto à linha de costa mesmo sobre a praia, desconsiderando a morfologia e, sobretudo, a dinâmica dos ambientes costeiros (problemas de erosão). O uso turístico voltado para a navegação de recreação se caracteriza, principalmente, pela necessidade de marinas e portos, que são relativamente escassos na costa paranaense (PIERRI et al., 2006).

O modelo de ocupação urbana segundo Sampaio (2006) segue o parcelamento do solo, na forma de loteamentos - chamados balneários - com predominância quase absoluta de localização com frente para praia, e, na maioria das vezes, sem continuação, continente adentro. Loteamentos, produto de iniciativa privada, de empresa ou família, muitos são colocados à venda sem presença de qualquer infraestrutura técnica, constituindo-se apenas por um arruamento aberto na restinga (figuras 05 e 06). Verifica-se ainda, existência de construções irregulares na faixa costeira, com usos de moradia e comércio nos balneários. A ocupação da orla e supressão da vegetação de restinga, dada sua importância na estabilidade da dinâmica no ambiente de transição entre o meio marinho e o terrestre, vem sofrendo fortes pressões ao longo dos anos.


Figura 05 e 06

Ocupação inadequada da orla em Pontal do Paraná e Paranaguá (1955)

respectivamente.

(Fonte: Figura 05 www.omelhordolitoralparana.blogspot.com/2011/07/fotosparanagua.html. Figura 06 - Projeto ORLA, Pontal do Paraná, 2004). 
Embora historicamente e frequentemente desrespeitado, é notário o conhecimento cientifico, bem como a regulamentação ambiental fixando conhecer a dinâmica de algumas praias do Paraná, o que permite estabelecer faixas de segurança mínimas que deveriam ser respeitadas na ocupação das planícies litorâneas. Essas faixas oscilam $50 \mathrm{~m}$ a $120 \mathrm{~m}$ nas costas mais estáveis e instáveis, respectivamente, podendo ser maiores, onde, nos últimos 30 anos as variações foram maiores que $120 \mathrm{~m}$. Como a ocupação atual muitas vezes ultrapassa essas faixas é necessário, verificar cada caso para estabelecer a faixa de segurança viável e controlar o uso das áreas ocupadas (ANGULO, 2000).

O turismo de praia se consolida em função do climaltempo, e é responsável pela atração do fluxo de visitantes. Muitas vezes é sazonal e massivo, contribuindo para a perda de qualidade ambiental e desgaste da imagem dos destinos turísticos. O turismo no litoral do Paraná de acordo com a Secretaria de Turismo do Estado (SETU) tem sua maior demanda no período de dezembro a fevereiro, quando passa pela região número superior a um milhão de visitantes, buscando principalmente o sol e as praias, como também ecoturismo, turismo náutico e turismo de aventura que são explorados ao longo do ano, os quais dependem das condições do tempolclima para sua prática.

Em relação à organização turística dos municípios, observa-se que todos eles possuem órgão oficial de turismo, sendo alvo de Pesquisa de Demanda Turística nos períodos de alta temporada (desde 1998) e baixa temporada (desde 2006), realizada pela SETU. Objetivado tornar o turismo no litoral mais competitivo, atraindo maior fluxo de turista, aumentando entrada de divisas nos destinos, há incremento do turismo na região em função dos projetos e programas instituídos, onde ações apoiam a qualificação e fortalecimento dos atrativos turísticos fazendo a região trabalhar cada vez mais no sentido de diversificar produtos ganhando novos mercados. Contudo, não se tem visto ações ou pesquisas que visem avaliar as intervenções do turismo nas mudanças climáticas - quer inversamente - sobre o peso que o turismo e atividades com ele relacionadas têm surtido nessas mudanças (SCOTT et al., 2009).

É imprescindível, tomar medidas de mitigação e adaptação, pois, quanto menos eficazes forem às mitigações, maiores serão as dificuldades para adaptações sociais e econômicas no futuro, destacando-se também regiões cuja economia depende quase exclusivamente do turismo.

Anastasiadis (2005) ao abordar as dificuldades de incorporação das ameaças do aquecimento global como problema social e econômico aponta que apesar de haverem evidências de que políticas de enfrentamento podem promover benefícios econômicos, o meio ambiente e a competitividade são atualmente compreendidos como mutuamente excludentes, as dificuldades de soluções alternativas concebíveis promovem arriscada confiança nas soluções tecnológicas - ainda indisponíveis - e, questões das mudanças climáticas são ignoradas por profissionais que não atuam na área ambiental.

O desafio, portanto, está em compatibilizar a ocupação do litoral com sua dinâmica analisando-a em diversas escalas espaciais e temporais. Prever o 
comportamento futuro da zona costeira frente às eventos climáticos extremos, globais ou regionais em processos de longo prazo; os processos locais de curto período observando os resultados de todos estes processos, nisso reside de acordo com Angulo (2004), a dificuldade de compreender a dinâmica das zonas costeiras.

\section{CONSIDERAÇÕES FINAIS}

As mudanças climáticas globais já estão em curso, provocando aumento da temperatura e mudanças nos regimes de precipitação, o que é esperado dentro do ciclo da natureza. Contudo, é possível atribuir alguns eventos extremos mais frequentes e intensos, como enchentes e secas prolongadas como consequência das ações antrópicas, gerando situações que impactam negativamente ecossistemas e a vida das populações. Apesar dos avanços nos modelos matemáticos para estudo do clima climáticos, existe uma enorme quantidade de variáveis não mensuráveis, dinâmicas e complexas que inviabilizam projetar a intensidade com que as mudanças afetarão o planeta.

Pesquisa mostra que $97 \%$ dos cientistas com produção ativa na área concordam que o aquecimento do clima global é real, perigoso e causado pelo homem. 0 eixo central da hipótese do aquecimento é argumentado diante ao ritmo acelerado dos gases do efeito estufa (GEE) oriundo da ação antrópica. A hegemonia de grande parte da comunidade científica sobre o aquecimento global torna ainda mais importante o cuidado e a necessidade de investigação sobre pesquisas que apresentam argumentações distintas, sobretudo, quando as mesmas representam importantes cientistas voltados aos estudos na área. Trata-se de um tema evidente no cenário de discussões atuais e, portanto, sob o risco de estar impregnado de modismos que ofusca o debate consistente e pode gerar julgamentos precipitados. Nesse âmbito, o desenvolvimento das reflexões apresentadas no artigo foi oportuno para articulação, em linhas gerais, de como a visão hegemônica de um paradigma cientifico pode acarretar em comportamentos tendenciosos ou manejo de planos de ações envolvendo a relação ambiente e desenvolvimento.

No que tange a relação turismo e mudanças climáticas, a revisão literária denota que o investimento em pesquisa sobre o tema no Brasil é pouco expressiva, não havendo adaptação ou desenvolvimento de metodologias que possam auxiliar ao setor turístico em pesquisa e ações de mitigação das mudanças climáticas. Diferente da realidade da Ásia, Europa ou América do Norte, onde efeitos dos eventos climáticos extremos têm ocasionado perdas humanas e econômicas, e talvez por essa razão as pesquisas tenham sido desenvolvidas de maneira mais vigorosa.

Objetivando neste artigo, tecer reflexões para tentar compreender se é possível estabelecer relações consistentes entre mudanças climáticas globais e a realidade local vivenciada nos destinos turísticos do litoral paranaense, pode-se 
considerar que esta trajetória mostrou-se complexa, sobretudo quando confrontada a discrepância entre discursos científicos, ideológicos e políticos, incompatíveis para efetivação de planos de mitigação de impactos socioambientais envolvendo os destinos turísticos do litoral paranaense. Essas questões devem ser levantadas para subsidiar um debate destinado a orientar o planejamento de ações voltadas ao enfrentamento dos variados efeitos decorrentes das mudanças climáticas. Inundações, secas, elevação do nível do mar, por exemplo, não constituem fatos novos nem eventualidades extremas decorrentes das mudanças climáticas globais.

Quanto ao processo de elevação do nível do mar, destinos turísticos do litoral paranaense devem estar atentos para discutir medidas que visem o planejamento das novas construções para que não ocupem áreas de risco, evitando assim, prejuízos dos investimentos públicos e privados em consequência da erosão costeira. Faz-se necessário estudar formas de proteção do litoral, ao avanço do mar, com alternativas que garantam continuidade de atividades socioeconômicas que possam ser afetadas caso elevação do nível do mar afete significativamente as áreas nas quais estão instaladas. Porém, devese considerar que, mesmo que as previsões de elevação do nível do mar se confirmem, o efeito desta elevação sobre as zonas costeiras deve ser diferente de acordo com suas características específicas e sua história evolutiva (ANGULO, 2004).

As mudanças climáticas devem produzir variações no clima, alterando períodos de chuva e seca. A possibilidade de que ocorra redução da capacidade hídrica em decorrência das mudanças climáticas e a intensificação da ocupação e adensamento dos municípios litorâneos pelos empreendimentos turísticos merecem uma atenção especial, uma vez que tais empreendimentos produzem impactos diretos nas reservas hídricas da Zona Costeira, verificando-se a necessidade de realização de estudos destinados à avaliação da vulnerabilidade, capacidade de suporte e modelo de gestão desses recursos.

A erosão costeira poderá ser gradativamente, intensificada com o aumento do nível dos oceanos, acarretando também a salinização dos solos e submersão de áreas baixas, ocasionando danos em várias estruturas urbanas e em algumas importantes atividades produtivas implantadas na faixa litorânea. Cenários futuros dos processos erosivos no litoral do Paraná visualizados por Angulo (2004) entre outras possibilidades destaca-se a estabilidade nas praias oceânicas sem ocupação ou cuja ocupação está recuada em relação a linha de costa; continuação da tendência erosiva do setor norte da Praia do Farol, na Ilha do Mel; aumento da erosão praial na Praia Central de Matinhos pelas obras rígidas muros, enrocamento e gabiões. Na parte norte desta praia pode haver estabilidade devido a retirada de residências e liberação de uma faixa sem ocupação; aumento da erosão na parte norte de Praia Brava de Caiobá, devido a invasão da praia e pelas obras de controle de erosão.

Este cenário requer o estabelecimento de estratégias destinadas a proteger o patrimônio construído na faixa da orla. A realização de pesquisas para identificar 
prováveis efeitos da elevação do nível do mar sobre as cidades e atividades que fornecem a sustentação econômica no litoral paranaense possibilitará a seleção dos espaços a serem protegidos e a captação dos recursos necessários para implantação das obras de proteção costeira, como já acontece em vários países que se anteciparam, instalando obras de contenção do avanço do mar para preservar suas cidades e atividades econômicas.

Analisando-se detidamente as complexas relações entre o turismo e mudança climática, e, em particular os efeitos que este último gera em diferentes destinos turísticos, nota-se que são necessárias medidas no setor para adaptar-se às instáveis condições do clima, adotando ações preventivas para enfrentar possíveis futuros efeitos das mudanças climáticas, assim como minimizar o impacto que o turismo produz sobre o meio ambiente. Da mesma maneira são necessárias medidas que visem à adequação das políticas públicas do turismo e mudanças climáticas subscrevendo todos os acordos intergovernamentais, governamentais e multilaterais afins, na busca de soluções associadas que previnam a incidência deste fenômeno em escala global, regional e local.

Por envolver muitas nações e considerando que o turismo refere-se a uma atividade econômica rentável, há especial atenção dos organismos oficiais de turismo, como a OMT em fomentar pesquisas, eventos e canais de divulgação sobre o tema. Contudo, tais informações precisam ser devidamente analisadas por instituições acadêmicas que apoiem aos governos locais e às organizações de gestão de destinos na aplicação de medidas de adaptação e mitigação que respondam aos efeitos específicos da mudança climática. Do mesmo modo, os resultados de qualquer investigação relevante sobre mudança climática e o turismo, devem constituir uma base de dados sobre o tema para difusão do conhecimento e metodologia de trabalho, possibilitando adequação e aplicação em diferentes escalas, pois, a constante relação de interdependência entre o local, regional e global, evidencia que, para compreensão dos fenômenos naturais em nível macro é importante enxergar peculiaridades daqueles que vivem na esfera local.

Nesse momento, é cabível expor suspeitas de que a institucionalização por muitas vezes, não apresenta funcionalidade ou ainda são sistemas regulatorios subutilizados, ignorados ou mesmo não refletem a realidade local. Qualquer que seja a situação a atuação é inocua, tornando inoperante ações mitigadoras que tenham algum significado plausível.

Do mesmo modo, observando o caminho inverso dessa abordagem é questionável a validade de julgamentos sob a responsabilidade turistica como deflagadora de mudanças climáticas. Talvez, mais modestamente, essas alterações em escala local ou regional apresentem impactos ambientais severos e localizados, que podem ser detectados nas pesquisas in loco, para posterior projeções ou consolidação de dados numa tentativa de projeção global. Apesar dos modelos do IPCC serem desenvolvidos em alta resolução, ainda carece de conhecimentos a nível microclimático, podendo gerar previsões pouco precisas. Todavia, esses aspectos devem ser minimizados com o passar do tempo e estes 
não devem ser considerados como percalços às imprescindíveis ações de mitigação e adaptação a este fenômeno que é, senão o maior, um dos maiores desafios deste século.

Diante ao cenário de incertezas, as hipóteses sobre mudanças climáticas devem ser analisadas considerando-a como um fenômeno complexo, relativo, volátil e compatível com a experiência cientifica que acredita na "certeza da incerteza" (Demo) e admite a importância do principio da incerteza e da precaução.

\section{REFERÊNCIAS}

ANASTASIADIS, S. The big problem in understanding climate change. Peace Review: A Journal of Social Justice, v. 17, 2005, p. 299-303.

ANDRADE, J. V. de. Turismo: Fundamentos e dimensões. $8^{a}$ Ed. Editora Àtica: São Paulo, 2006, p. 99 - 152.

ANGULO, R. J. Aspectos físicos das dinâmicas de ambientes costeiros, seus usos e conflitos. Revista Desenvolvimento e Meio Ambiente. Editora UFPR: Curitiba; 2004. no. 10, p. 175-185, jul./dez.

As Praias do Paraná: problemas decorrentes de uma ocupação inadequada. Revista Paranaense de Desenvolvimento. Curitiba, no. 99, p. 97-103, jul./dez. 2000

Comissão de Turismo e Desporto da Câmara dos Deputados. Mudanças climáticas: o turismo em busca de coeficiencia. Brasília, 2008. Disponível em:

http://bd.camara.gov.br/bd/bitstream/handle/bdcamara/1745/mudancas_climati cas_turismo_desporto.pdf?sequence=1. Acessado em 05 de setembro de 2012 .

CUNHA, L. H. Ordens e Desordens Socioambientais: saberes tradicionais em dinâmicas pesqueiras da costa paranaense. Tese (Doutorado) Universidade Federal do Paraná. Curitiba, 2007, 204p.

DAVOS DECLARATION. Climate change and tourism responding to global challenges. Davos, Switzerland, outubro de 2007.

DIAS, J. A.; MAHIQUES, M. M.; CEARRETA, A. Gestão Costeira: resultado de uma relação dúbia entre o Homem e a Natureza. Revista de Gestão Costeira Integrada / Journal of Integrated Coastal Zone Management; 2012, 12(1), p. 3-6.

FELICIO, R. A.; ONÇA, D.S. Os Mitos sobre o Ozônio: Um Resgate das Origens da Discussão - I. Fórum Ambiental da Alta Paulista, v. 8, p. 1-26, 2012.

GOSSLING, S. Tourism's contribution to global environmental change: space, energy, disease, water. In Hall C M, Higham J (Org.) Tourism, recreation and climate change, Channel View Publications, Clevedon, 2005; p. 286 300 .

GRIMM, I. J. Planejamento Territorial: uma metodologia de monitoramento de Indicadores Socioambientais na Microbacia Hidrográfica do Rio Sagrado, Morretes (PR). Dissertação (Mestrado em Desenvolvimento Regional). FURB: Blumenau, 2010, 210p. 
HU, Y.; \& RITCHIE, J. Measuring destination attractiveness: a contextual approach. Journal of Travel Research, 1992, p. 25-34.

IPCC (Intergovernmental Panel on Climate Change). Fourth Assessment Report of the United Nations Intergovernmental Panel on Climate Change, Cambridge University Press, Cambridge, UK, 2007.

Kozak, N., Uysal, M. \& Birkan, I. An analysis of cities based on tourism supply and climatic conditions in Turkey. Tourism Geographies, 2008, 10(1), 81-97.

MARANDOLA Jr. E. "Tangenciando a vulnerabilidade". In: HOGAN, Daniel J. e MARANDOLA Jr. E. (orgs.): População e mudança climática: Dimensões humanas das mudanças ambientais globais. Campinas, SP: Núcleo de Estudos da População (Nepo), Unicamp; Brasília, UNFPA, 2009.

MATZARAKIS, A. Clima e turismo - implicações e perspectivas. 2008. Disponível em: www.ceg.ul.pt. Acessado em 07 de setembro de 2012.

MENDONÇA, F.; DANNI-OLIVEIRA, I. M. Climatologia - Noções básicas e climas do Brasil. São Paulo: Editora Oficina e Textos, 2007.

MENDONÇA, F. et al. A intensificação do efeito estufa planetário e a posição dos países no cenário internacional. RA'E GA - 0 espaço geográfico em analise, n. 5, ano V, Curitiba-PR, Editora da UFPR, 2006. p. 99-124.

MENDONÇA, F. Aquecimento Global e suas manifestações regionais e locais: alguns indicadores da região sul do Brasil. Revista Brasileira de Climatologia, Vol. 2, p. 2011, 71-86. ISSN.

MILANKOVITCH, M. Canon de insolação e o Problema Idade do Gelo. Israel Programa de tradução científica. Jerusalém (1969); 1941.

MOLION, L.C.B. Variabilidade e forçantes climáticas, Anais do XIV Congresso Brasileiro de Meteorologia. Florianópolis. SBMET, 27 a 4 de dezembro de 2006.

ODUM, E. P. Ecologia. Rio de Janeiro: Guanabara, 1988.

ORGANIZAÇÃO MUNDIAL DO TURISMO - OMT. Cambio climático y turismo: Responder a los retos mundiales, 2007. Disponível em: http://sdt.unwto.org/sites/all/files/docpdf/summarydavoss.pdf. Acessado em 10 de setembro de 2012.

PARANÁ. Instituto Ambiental do Paraná - IAP. Disponível em http://www.uc.pr.gov.br/arquivos/File/Plano_de_Manejo/APA_Guaratuba/Plano_ de_Manejo_APA_de_Guaratuba.pdf. Acessado em 28 de novembro de 2009.

PIERRI, N.; ÂNGULO, R.; SOUZA, M C. de; KIM, M. K. A ocupação e o uso do solo no litoral paranaense: condicionantes, conflitos e tendências. Revista Desenvolvimento e Meio Ambiente. Editora UFPR: Curitiba; 2006 n. 13, p. 137-167, jan./jun.

SAMPAIO, R. Ocupação das orlas das praias paranaenses pelo uso balneário. Revista Desenvolvimento e Meio Ambiente. Editora UFPR; n. 13, p. 169186, jan./jun. 2006. 
SCOTT, D.; DE FREITAS, C.R.; MATZARAKIS, A. Adaptation in the tourism and recreation sector. In: Biometeorology for adaptation to climate variability and Chang .(Org.) MCGREGOR, G.R.; BURTON, I.; EBI, K., 2009; p. 171 -194

\section{Secretaria}

Estadual

de

Turismo

SETU.

http://www.setu.pr.gov.br/arquivos/File/Planos/PlanoLitoraldoParana.pdf.

Acessado em 14 de setembro de 2012.

VANHONI, F.; MENDONÇA, F. O clima no litoral do Paraná. Revista Brasileira de Climatologia. ISSN: 1980-055X. 2008, p. 49-63. 